\section{NASAL RECONSTRUCTION}

\section{Peerzada Umar Farooq Baba, Adil Hafeez Wani}

Department of Plastic surgery, SKIMS, Soura

\section{SHORT CLINICAL HISTORY AND PROCEDURE:}

A 65-year male presented with squamous cell carcinoma of the left side of the nose. Wide local excision of the tumor with reconstruction by ipsilateral forehead flap was done. After 3 weeks flap was detached giving a good functional as well as an aesthetic result.

\section{Written informed consent was taken from the patient.}

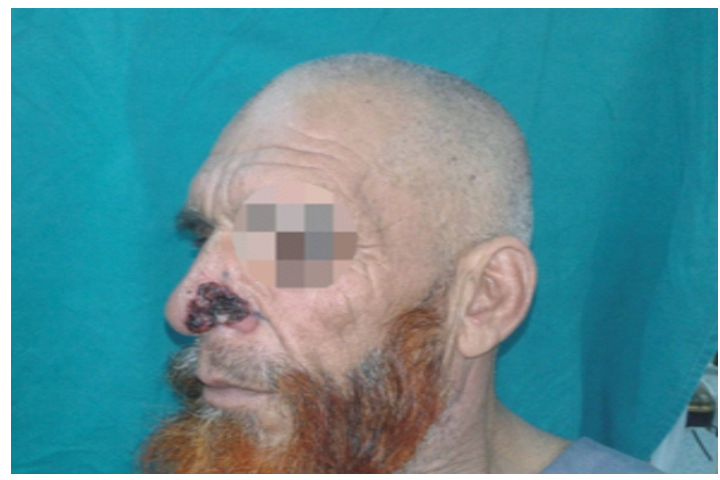

Squamous Cell Carcinoma on Left Side of Nose

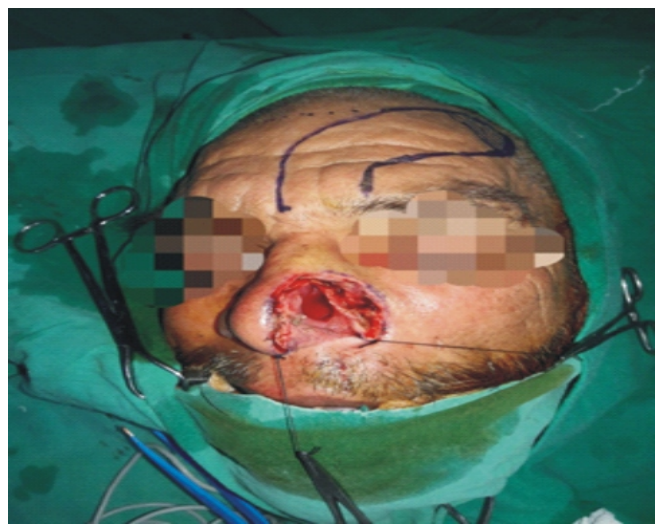

Tumour Excision Performed and Markings for Forehead Flap Done

\begin{tabular}{l|l|l|}
\hline & Access this article online \\
\hline
\end{tabular}

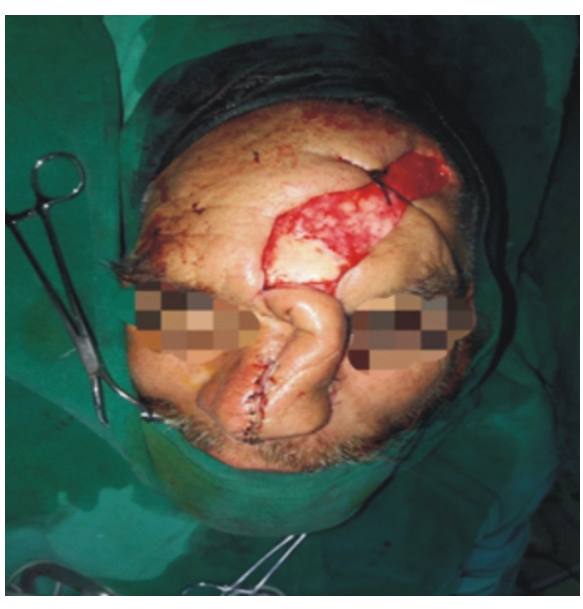

Nasal Defect Covered by the Flap

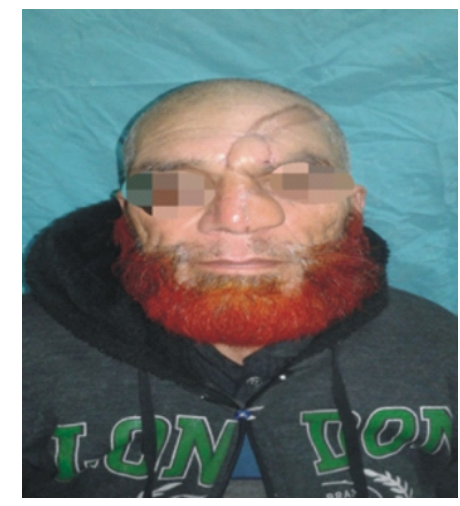

Detachment of Flap and Final Insetting

Correspondence:

Dr. Peerzada Umar Farooq Baba, MS

Associate Professor, Department of Plastic surgery, SKIMS Email:drumar397@gmail.com

How to cite this article: Baba PUF, Wani AH. NASAL RECONSTRUCTION.JMS 2020; 23(3):38

Received: 2020-08-28 Accepted: 2020-09-01 (CC BY 4.0), which permits unrestricted use, distribution, and reproduction in any medium, provided the original author and source are credited. 